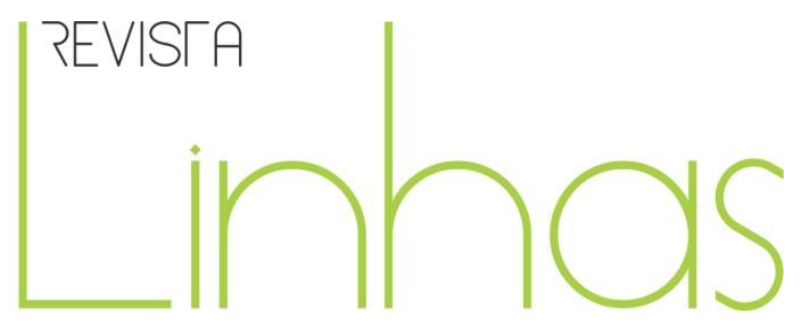

\title{
O ensino brasileiro de Álgebra segundo a revista "A Escola Primaria" (1917-1928)
}

\section{Resumo}

Discussões acerca do ensino da Álgebra ganharam grande relevância no início do século XX devido aos debates e propostas de inserção de tal matéria no currículo do ensino elementar ${ }^{1}$. Neste texto, busca-se compreender os discursos acerca do ensino de Álgebra postos em circulação pelo periódico da época, "A Escola Primaria", durante seu período de publicação, assim como, reconstituir o conhecimento disseminado pela revista, de forma a melhor conceber o processo de inserção da Álgebra no ensino elementar no país. Para isso, é proposta a metodologia de um estudo histórico, com base na História da educação matemática, em conjunto com um Estado do Conhecimento. A análise dos artigos aponta que alguns autores difundiram um movimento a favor da constituição de uma Álgebra voltada para o ensino elementar. Essa Álgebra teria como principais focos apresentar o processo de generalização e facilitar a resolução de problemas de Aritmética que, sem esses saberes algébricos, exigiriam raciocínios extensos e cansativos, tornando sua presença no ensino ponto de críticas.

Palavras-chave: estado do conhecimento; ensino de álgebra; circulação de ideias; história da educação matemática.
Jeremias Stein Rodriguês

Instituto Federal de Santa Catarina -

IFSC - Florianópolis/SC - Brasil

jeremias.stein@ifsc.edu.br

Anieli Joana de Godoi

Secretaria de Estado da Educação

de Santa Catarina - SED/SC -

Florianópolis/SC - Brasil

anieligodoi@gmail.com

\section{David Antonio da Costa}

Universidade Federal de Santa

Catarina - UFSC - Florianópolis/SC Brasil

david.costa@ufsc.br

\section{Para citar este artigo:}

RODRIGUÊS, Jeremias Stein; GODOI, Anieli Joana de; COSTA, David Antonio da. O ensino brasileiro de Álgebra segundo a revista "A Escola Primaria" (1917-1928). Revista Linhas. Florianópolis, v. 22, n. 50, p. 266292, set./dez. 2021.

\section{DOI: $10.5965 / 1984723822502021266$}

http://dx.doi.org/10.5965/1984723822502021266

\footnotetext{
* O presente trabalho foi realizado com apoio do Programa de Bolsas Universitárias de Santa Catarina do Fundo de Apoio à Manutenção e ao Desenvolvimento da Educação Superior (UNIEDU/FUMDES) PósGraduação vinculado à Secretaria de Estado da Educação de Santa Catarina.

${ }^{1}$ Considera-se aqui como ensino elementar todo ensino que ocorreu anteriormente ao ensino secundário. Essa nomenclatura foi adotada pelas diversas denominações neste ensino, algumas vezes chamado de ensino primário e complementar ou apenas de primário, ou ainda de primário de $1^{\circ} \mathrm{e} 2^{\circ}$ grau.
} 


\title{
The brazilian teaching of Algebra according to the journal "A Escola Primaria" (1917-1928)
}

\begin{abstract}
Discussions about the teaching of Algebra gain great relevance in the beginning of the XXth century due to debates and proposals of insertion of such subjects in the curriculum of the elementary school. In this text an attempt was made to comprehend the speeches about the teachings of Algebra circulated in Brazil through the periodic "A Escola Primária" in the beginning of the XXth century as well as reconstruct the knowledge disseminated by the journal, in order to best conceive the process of insertion of Algebra in the country's elementary school. For this, it is proposed a methodology in the historical study, taking as a base the History of mathematics education, together with a State of Knowledge. The analysis of articles points that some authors spread through Brazil a movement for the constitution of Algebra for the elementary school. This Algebra would have as primary focus to present the process of generalization and facilitate the resolution of Arithmetic problems that, without this algebraic knowledge, would need extensive and tiring arguments, making its presence in education a criticized matter.
\end{abstract}

Keywords: state of knowledge; algebra teaching; circulation of ideas; history of mathematics education. 


\section{Introdução}

O início do século XX marca no Brasil um período em que a Álgebra se torna presente nas discussões acerca do ensino elementar e secundário. Tal movimento talvez tenha se dado pelo fato de que nos Estados Unidos, no fim do século XIX, estudos sobre a inserção da Álgebra no ensino elementar tenham sido desenvolvidos por duas comissões, a Comissão dos dez e a Comissão dos quinze, que buscavam reestruturar os sistemas de ensino secundário e elementar no país, respectivamente (RODRIGUÊS; COSTA, 2019). Segundo estes autores (RODRIGUÊS; COSTA, 2019), uma das conclusões das comissões foi de se constituir um ensino de Álgebra nos dois últimos anos do ensino elementar, algo relevante mesmo para o ensino secundário, uma vez que o estudante ingressante estaria melhor preparado para dar continuidade à sua instrução. A partir de uma conferência realizada por Othello de Souza Reis (1918a, 1918b), intitulada "Os dois ultimos annos de arithmetica, na escola primaria, segundo a Commissão dos Quinze" e que depois veio a ser publicada na revista "A Escola Primaria”, é possível notar que o debate estadunidense chega ao Brasil no início do século seguinte, indicando não apenas que a proposta de constituição de uma Álgebra para o ensino elementar tenha ingressado ao país, mas também que outras discussões sobre o ensino de Álgebra tenham feito parte do cenário brasileiro.

Em sua conferência, Reis (1918a, p. 12) indica que sua fala é abonada por diversos autores, inclusive pelo brasileiro Francisco Cabrita, que teria publicado dois trabalhos acerca da Álgebra no ensino e na formação de professores normalistas. Os trabalhos de Reis (1918a, 1918b) e Cabrita (1917a, 1917b) mostram que as discussões a respeito do ensino de Álgebra no Brasil tiveram ampla divulgação na revista "A Escola Primaria”, na qual se podem encontrar as publicações dos dois autores. Assim, parece natural questionar: quais outros debates o periódico ajuda a disseminar pelo país, ou, com base no referencial utilizado, quais conjuntos de ideias a revista permite circular no âmbito brasileiro durante seu período de publicação?

Nesta perspectiva, este trabalho se apoia nos estudos da História da educação matemática (Hem), quando se abordam questões acerca do ensino de Álgebra nos primeiros anos escolares. Para tanto, considera-se a Hem como "um tema dos estudos 
históricos, uma especificidade da história da educação" (VALENTE, 2013, p. 24), que de algum modo auxilia na compreensão de desafios em sala de aula do presente.

De modo que a importância de sua produção se deve pelo fato de que

[...] um professor de matemática que mantenha uma relação a-histórica com os seus antepassados profissionais possa, com a apropriação dessa história, se relacionar de modo [...] mais científico com esse passado. Isso tende a alterar as suas práticas cotidianas, que passam a ser realizadas de modo mais consistente. (VALENTE, 2013, p. 28)

Tais diálogos levam os pesquisadores a refletir acerca de suas metodologias de ensino, bem como, a compreender os processos de ensino de determinada época. Diante disso, há uma grande necessidade de conhecer as transformações que acontecem nas escolas, dentro das salas de aula. Segundo Valente (2003), essas modificações levam os historiadores a voltarem seu olhar para as instituições de ensino, de modo que estas vêm se transformando no lugar de posicionamento dos historiadores da educação.

Neste sentido, de acordo com Valente (2010), o professor de matemática, na sua lida diária, necessita compreender como suas práticas e saberes se relacionam com perspectivas do passado e como estas foram sendo reelaboradas no decorrer do tempo. Isso também ajuda o professor de matemática a pensar sobre os métodos que utiliza e entender o porquê de alguns deles apresentam resultados mais satisfatórios do que outros.

Deste modo, com o intuito de responder a pergunta "quais contribuições acerca do ensino de Álgebra circulavam através do periódico 'A Escola Primaria' durante seu período de publicação?", um levantamento dos trabalhos publicados nesta revista foi necessário, de forma que a pesquisa tenha se moldado como um Estado do Conhecimento. Para isso uma busca por artigos da revista foi realizada na Hemeroteca Digital$^{2}$, utilizando o descritor "algebra", para estabelecer quais as publicações que buscaram circular no Brasil a discussão acerca do ensino de Álgebra e quais discussões eram propostas pelas mesmas. Os trabalhos encontrados foram posteriormente analisados sob a perspectiva da História da educação matemática, de forma a constituir

\footnotetext{
${ }^{2}$ Disponível em: http://bndigital.bn.gov.br/hemeroteca-digital/.
} 
uma narrativa histórica relacionada ao tema e estabelecer quais elementos e discussões fizeram parte do movimento de circulação de ideias acerca do ensino de Álgebra.

\section{Referencial teórico-metodológico empregado}

A Hem como campo de pesquisa se apoia nos estudos da História da Educação e na utilização do ferramental teórico-metodológico dos historiadores. Assim, ao se tratar do referencial teórico, são consideradas as perspectivas de Certeau (2010), quando aborda o conceito de historiografia, no qual o procedimento de escrita se baseia em um lugar social, em que o historiador e sua fala tomam posições de relevância, constituindose assim como um lugar de produção histórica; uma prática que relaciona os saberes naturais e culturais, na qual tudo começa com a separação, reunião e transformação em documentos dos objetos distribuídos de maneira diferente, sempre respeitando os elementos que cada documento traz e o que já foi narrado sobre ele; uma escrita, que seria o produto final da historiografia, que consiste na elaboração de um texto histórico, de uma literatura, que relate mais do que um fato, mas a história de um lugar.

Da mesma forma, Veyne (1995) argumenta que a escrita histórica deve ser considerada como uma narrativa, de modo que a história é conhecimento mediante os documentos e é a partir deles que se consegue fazer uma escrita dos fatos. Entendendo que "os acontecimentos não são coisas, objetos consistentes, substâncias; eles são um corte que realizamos livremente na realidade, um aglomerado de procedimentos em que agem e sofrem substâncias em interação, homens e coisas" (VEYNE, 1995, p. 30), e é este conjunto que possibilita compreender a história que se quer descrever.

Segundo Ferreira (2002), denominadas de "estado da arte" ou "estado do conhecimento", tais pesquisas definidas como de caráter bibliográfico, são também reconhecidas por apresentarem uma metodologia de caráter inventariante e descritivo da produção acadêmica e científica sobre o tema, que busca investigar e trazer o desafio de mapear e de discutir uma certa produção acadêmica em diferentes campos do conhecimento, tentando responder que aspectos e dimensões vêm sendo destacados e privilegiados em diferentes épocas e lugares. Assim, esses estudos "permitem a compreensão do movimento da área, sua configuração, propensões teóricas 
metodológicas, análise crítica indicando tendências, recorrências e lacunas" (VOSGERAU; ROMANOWSKI, 2014, p. 167). Para tanto, permitem algum mapeamento sobre determinado tópico e buscam colocar em evidência os temas e assuntos focalizados, as abordagens metodológicas, os procedimentos e análises, favorecem o exame das contribuições da pesquisa, na perspectiva da definição da área, do campo e das disciplinas que o constituem.

Em mapeamentos como este, para Romanowski e Ens (2006, p. 39), tem-se a possibilidade de "contribuir com a organização e análise na definição de um campo, uma área, além de indicar possíveis contribuições da pesquisa para com as rupturas sociais". Do mesmo modo que "podem significar uma contribuição importante na constituição do campo teórico de uma área de conhecimento, pois procuram identificar os aportes significativos da construção da teoria e prática pedagógica" (ROMANOWSKI; ENS, 2006, p. 39). De forma semelhante, segundo Romanowski e Ens (2006, p. 40), observa-se que tal modalidade de estudo "é também uma possibilidade de perceber discursos que em um primeiro exame se apresentam como descontínuos ou contraditórios", mas que, quando comparados e reunidos com outros, trazem elementos ricos e bem consolidados acerca de determinado assunto e que se tornam úteis na construção de um texto.

Desse modo, neste texto, teve-se o intuito de analisar as produções de um periódico brasileiro voltado para o ensino elementar no país, na busca pelas discussões sobre o ensino de Álgebra para este nível de instrução. Ao desenvolver uma investigação neste tipo de fonte, com o propósito de caracterizar a produção de conhecimento em um dado meio de produção científica e em um dado período, a pesquisa assume a perspectiva de um Estado do Conhecimento, ao entender que se aborda apenas um setor de publicação do tema estudado, neste caso a revista "A Escola Primaria" (ROMANOWSKI, ENS, 2006) $)^{3}$.

Contudo, talvez seja necessário questionar a relevância de um Estado do Conhecimento sobre as publicações de um passado há muito distante. Inicialmente, sob a lente da historiografia, tal estudo revela não só uma parte da história do ensino e dos debates da Álgebra na escola, mas, além disso, ele permite observar os traços do passado

\footnotetext{
3 Um "estado da arte" sobre o tema iria se debruçar sobre outras produções, tais como: periódicos, livros, trabalhos publicados em anais de eventos etc.
} 
que possibilitam a construção dessa narrativa histórica. O ofício de quem escreve tal história se constitui a partir do "[...] processo de interrogação que se faz aos traços deixados pelo passado, que são conduzidos à posição de fontes de pesquisa" (VALENTE, 2007, p. 39) pelas questões postas pelo pesquisador. Muitos desses traços, ou fontes, só existem devido ao movimento de preservação e divulgação, como a publicação de livros e revistas.

Assim, a partir das perspectivas metodológicas de Estado do Conhecimento, a história cultural assume o papel teórico metodológico, ditando sobre a construção de uma narrativa histórica por meio da interação do pesquisador com as fontes. Deste modo, além de se constituir a produção teórica acerca de um tema, finalidade do Estado do Conhecimento, o pesquisador tem como objetivo (re)construir uma história concretizada a partir de uma narrativa, aqui referente à circulação de um discurso por meio da revista, na qual o posicionamento do investigador-autor se faz presente. A pesquisa assume, então, por meio desta proposta teórico-metodológica, o caráter de um Estado do Conhecimento Histórico ${ }^{4}$ voltado às publicações da revista "A Escola Primaria".

No período do estudo, os periódicos relacionados à educação são, em sua maioria, escritos por professores, que por sua vez estão integrados a associações ou comissões que se relacionam à docência. Acredita-se que esse tipo de publicação pode revelar os pensamentos e as concepções desses autores, elemento de grande importância em estudos históricos. Visto que, segundo Catani,

O fato das revistas de ensino fazerem circular informações sobre o trabalho docente, a organização dos sistemas de ensino, as lutas da categoria profissional do magistério, bem como os debates e polêmicas que incidem sobre aspectos dos saberes ou das práticas pedagógicas, tornam as mesmas uma instância privilegiada para a investigação dos modos de funcionamento do campo educacional. (CATANI, 1996, p. 116)

\footnotetext{
${ }^{4}$ Do mesmo modo poderia se definir um Estado da Arte Histórico, desde que a pesquisa se debruçasse sobre as diversas fontes de produção do conhecimento em educação da época e local.
} 
Além disso, deve-se ressaltar também, que em épocas que havia escassez de livros didáticos, as revistas tinham um grande papel no ensino. E assim:

As revistas eram, por sua vez, também, utilizadas como ferramenta estratégica da elite dirigente para atingir os professores, transmitindoIhes informações técnicas de atuação profissional. Para os professores, uma tática profissional no sentido que lhes davam mais segurança no trato com as questões técnicas e/ou pedagógicas, que pode também ser entendida como uma estratégia destes perante os alunos. (OLIVEIRA FILHO, 2015, p. 157-156)

Deste modo, "acompanhar o aparecimento e o ciclo de vida dessas revistas permite conhecer as lutas por legitimidade, que se travam no campo educacional" (CATANI, 1996, p. 117) da época, além de conhecer o que estava se falando sobre a educação, o ensino e a matemática. De acordo com Costa:

[...] as revistas pedagógicas são importantes fontes de informação para as pesquisas históricas. Tomando as mesmas como suporte material para normatizar as práticas escolares dos professores, suas análises podem revelar pontos de associação entre teoria e prática escolares e políticas envolvendo valores afins. (COSTA, 2015, p. 440)

Dessa maneira, há a possibilidade de se mapear acontecimentos pedagógicos, analisando as alterações e permanências que o ensino teve, em determinada passagem do tempo. Para tanto, as revistas especializadas em educação

[...] constituem uma instância privilegiada para a apreensão dos modos de funcionamento do campo educacional enquanto fazem circular informações sobre o trabalho pedagógico e o aperfeiçoamento das práticas docentes, o ensino específico das disciplinas, a organização dos sistemas, as reivindicações da categoria do magistério e outros temas que emergem do espaço profissional. (CATANI, 1996, p. 117)

Além disso, vale destacar que é possível tomar os periódicos educacionais antigos “[...] como núcleos informativos, enquanto suas características explicitam modos de construir e divulgar o discurso legítimo sobre as questões de ensino e o conjunto de prescrições ou recomendações sobre formas ideais de realizar o trabalho docente" (CATANI, 1996, p. 118). 
A difusão do impresso tem, então, grande relevância para o desenvolvimento de pesquisas historiográficas, e esta, por vezes, está atrelada ao processo de circulação de ideias. Nesse sentido, é a partir de Chartier (1990) e Burke (2016) que se compreende o conceito de circulação de ideias. Para Burke (2016), este movimento, denominado pelo autor de "disseminação do conhecimento", é concebido como um processo em que alguém ou algum objeto transmite um conhecimento. Sob a perspectiva de Chartier (1990), a circulação de ideias é entendida a partir da apropriação de ideias, em que qualquer ser pensante, ao se apropriar de um conjunto de ideias, dá sentido àquilo que toma para si.

Assim, para Chartier (1990) a apropriação de ideias está ligada a um processo de interpretação, de dar sentido a algo, no que Burke (2016, p. 113) reforça dizendo que "precisamos lembrar que o conhecimento recebido não é igual ao conhecimento emitido, por causa dos mal-entendidos [...] e das adaptações deliberadas ou traduções culturais". Deste modo, a circulação de ideias é aqui compreendida como um processo constante em que a disseminação e apropriação buscam, respectivamente, difundir e divulgar um conjunto de ideias e dar sentido a tudo que se toma do processo em circulação. Pode-se observar, como consequência da circulação de ideias, a busca pela publicação das ideias que se quer disseminar ou mesmo apropriar, o que viabiliza o acesso a diversos discursos do passado.

A revista, então, pode ser vista como um agente de circulação de ideias que possui grande alcance, uma vez que ela permite o acesso de diversos leitores que se encontram distantes dos autores do impresso. Essa situação pode ser exemplificada pelo artigo do professor Othello de Souza Reis (1918a, 1918b), intitulado “Os dois ultimos annos de arithmetica, na escola primaria, segundo a Commissão dos Quinze" e publicado na revista em 1918. Essa publicação de Reis, pelo que os indícios apontam, é a transcrição de uma conferência realizada pelo autor em setembro de $1918^{5}$, posteriormente publicada na revista e no prefácio de seu livro “Algebra - primeiros passos”, em 1919. Assim, tanto a publicação na forma de artigo, quanto a publicação no início de seu livro, tornam possível que os diversos professores ou agentes da educação brasileira, que não estivessem em

\footnotetext{
5 Como pode ser observado nos “Anais da Biblioteca Nacional”, do Rio de Janeiro, disponível em: http://memoria.bn.br/DocReader/402630/19749.
} 
sua conferência, pudessem ter acesso às palavras e contribuições de Othello Reis. Do mesmo modo, nos dias de hoje, provavelmente não seria possível ter acesso a esse material caso esses impressos não tivessem buscado circular as ideias apresentadas pelo autor, o que denota que esta pesquisa historiográfica só se tornou possível devido aos diversos processos de circulação realizados no passado.

Logo, o Estado do Conhecimento não é utilizado aqui para realizar um levantamento dos trabalhos relacionados a um dado tema atual, uma vez que este é feito a partir de publicações do passado. Contudo, esta pesquisa toma aqui o papel de auxiliar na (re)construção de um passado distante, relacionado às discussões acerca da Álgebra no ensino a partir da revista "A Escola Primaria". Muito além disso, acredita-se que o Estado do Conhecimento, apoiado nos referenciais da circulação de ideias, permite compreender como as mesmas se deram a partir de um tema norteador.

Para o desenvolvimento do Estado do Conhecimento, um levantamento foi realizado na Hemeroteca Digital, espaço destinado ao acervo de alguns periódicos, com publicações que remontam ao ano de 1741. Neste ambiente virtual, puderam ser encontradas as publicações do periódico “A Escola Primaria”, com publicações entre 1916 e 1938. A escolha por tal periódico se deu pelo fato de que é possível observar, a partir do artigo de Othello Reis (1918a, 1918b), indícios da disseminação de ideias na busca pela institucionalização de uma Álgebra para o ensino elementar nas publicações da revista. Esse artigo também lança grande relevância para a discussão estadunidense acerca da constituição de uma Álgebra para o ensino elementar (RODRIGUÊS; COSTA, 2019). Assim, buscou-se, por meio desta pesquisa, investigar quais outras discussões sobre o ensino de Álgebra circularam nas revistas da época em âmbito brasileiro.

\section{O estado do conhecimento}

O acesso ao periódico "A Escola Primária" foi realizado por meio de pesquisa via Hemeroteca Digital. Ao pesquisar por "algebra" (o mesmo resultado surge com "álgebra") foram obtidas 50 menções ao termo nas edições da revista, entre os anos de 1916 e 1937. Após uma inspeção inicial, os resultados foram apontados em 32 edições da revista, dos quais apenas 12 apresentam discussões acerca da álgebra e não apenas citam 
o termo. De forma semelhante, ao realizar uma pesquisa utilizando o termo "algebrico", foram encontradas sete menções na revista, divididas em cinco edições da mesma. Contudo, nenhuma nova publicação, em relação com as 12 já encontradas, foi adicionada a partir desta segunda pesquisa. Nas 12 edições da revista, foram localizadas 12 publicações que se organizam em nove artigos, visto que três publicações são continuação de artigos apresentados em um número anterior. Nestes, percebem-se discussões acerca da álgebra ou do ensino de álgebra em diversos níveis escolares. No quadro 1, são apresentadas as informações iniciais sobre as publicações encontradas a partir da pesquisa.

Quadro 1 - As publicações encontradas a partir do levantamento

\begin{tabular}{|c|c|c|c|}
\hline Autor & Título & $\begin{array}{c}\text { Ano da } \\
\text { publicação }\end{array}$ & $\begin{array}{l}\text { Edição da } \\
\text { revista }\end{array}$ \\
\hline $\begin{array}{l}\text { Othello de Souza } \\
\text { Reis }\end{array}$ & $\begin{array}{c}\text { Os problemas resolvidos por } \\
\text { equações }\end{array}$ & 1917 & Anno 1, n. 9 \\
\hline Francisco Cabrita & A algebra do normalista & 1917 & Anno 1, n. 10 \\
\hline Francisco Cabrita & A algebra no ensino primario & 1917 & Anno 1, n. 12 \\
\hline Francisco Cabrita & Escola normal $^{6}$ & 1917 & Anno 2, n. 3 \\
\hline $\begin{array}{l}\text { Henrique Souza } \\
\text { Jardim }\end{array}$ & $\begin{array}{l}\text { Problemas de arithmetica na escola } \\
\text { primaria: como ensinar a resolvel-os }\end{array}$ & 1918 & $\begin{array}{l}\text { Anno 2, n. } 9 \\
\text { Anno 2, n. } 10 \\
\text { (cont.) }\end{array}$ \\
\hline $\begin{array}{l}\text { Othello de Souza } \\
\text { Reis }\end{array}$ & $\begin{array}{c}\text { Os dois ultimos annos de } \\
\text { arithmetica, na escola primaria, } \\
\text { segundo a Commissão dos Quinze }\end{array}$ & 1918 & $\begin{array}{l}\text { Anno 3, n. } 1 \\
\text { Anno 3, n. } 2 \text { e } \\
3 \text { (cont.) }\end{array}$ \\
\hline Francisco Cabrita & $\begin{array}{l}\text { Memoravel periodo historico da } \\
\text { Instrução Nacional }\end{array}$ & 1921 & Anno 5, n. 2 \\
\hline Francisco Cabrita & Analyse Indeterminada & 1922 & Anno 6, n. 4 \\
\hline $\begin{array}{l}\text { Iracema Torrents } \\
\text { Pereira }\end{array}$ & $\begin{array}{l}\text { Do ensino de Mathematica na } \\
\text { escola primaria }\end{array}$ & 1928 & $\begin{array}{l}\text { Anno 7, n. } 7 \\
\text { Anno 7, n. } 8\end{array}$ \\
\hline
\end{tabular}

Fonte: Elaborado pelos autores, 2021.

\footnotetext{
${ }^{6}$ Neste artigo, Cabrita faz menção ao termo "álgebra", mas tem como objetivo central discorrer sobre temas gerais da educação, como a crítica ao programa da escola normal com quinze matérias em um mesmo ano (CABRITA, 1917C). Contudo, o autor não aborda outros temas a respeito do ensino de Álgebra, ou de Aritmética, que pudessem ter contribuído para os debates da época.
} 
É possível observar nas primeiras edições disponíveis no acervo on-line que a editora “Francisco Alves \& C.”, com endereços nos municípios de Rio de Janeiro, São Paulo e Belo Horizonte, está em destaque na capa da "A Escola Primaria". Em alguns números, do $4^{\circ}$ ano da revista, sua impressão passa a ser feita pela livraria e editora "Leite Ribeiro \& Murillo", do Rio de Janeiro, mas logo a única informação que se observa é que a redação da revista se faz no Rio de Janeiro. Em quase metade das edições é apresentada, na capa do periódico, a indicação de que este estaria sob a direção dos inspetores escolares do Distrito Federal (o Rio de Janeiro neste período).

Afranio Peixoto escreve o editorial, onde lembra de Esther Pedreira de Melo, a primeira inspetora escolar do distrito federal, que idealizou a revista, e foi por ele encaminhada ao editor Francisco Alves, que se tornou o diretor da mesma, e no seu falecimento, foi substituído por Alfredo Cesário de Faria Alvim. (OLIVEIRA, 2015, p. 151)

Em parte das publicações também são apresentadas outras informações sobre a direção da revista. É possível observar que Alfredo Cesario de Faria Alvim e Yelva P. de Sá Freire foram, respectivamente, o diretor-presidente e a gerente da revista. Em outro período aparecem os nomes de Alfredo Alvim, como diretor, e Regina de Sá Freire Alvim, como gerente em uma única publicação. O nome de Regina Alvim volta ao impresso algum tempo depois, agora como "diretor-responsável”. Algum tempo depois, Alfredo Alvim retoma a posição de diretor do periódico, no que também se apresenta a informação de que ele ocuparia a função de superintendente de educação elementar, que, algum tempo depois, passaria a superintendente do ensino particular. Nas últimas edições da revista, o nome de Ruy Carneiro da Cunha também é apontado como diretor, sendo ele e Alfredo Alvim, superintendentes do departamento de educação. Como principal figura frente à revista, é importante destacar que Alfredo Alvim foi estudante na escola normal (NOTICIARIO, 1892, p. 3) e no externato do gymnasio no estado de Minas Gerais (EXTERNATO..., 1899, p. 8), no final do século XIX. Oliveira (2015) aponta, ainda, que Alfredo Alvim teria ocupado também a posição de presidente da Associação dos Professores Primários do Distrito Federal (RJ), sendo eleito em 1930.

De modo semelhante, é importante destacar a relevância de Francisco Cabrita nesta sondagem, uma vez que dos nove artigos encontrados, cinco são de sua autoria. 
Além disso, também se nota a presença de Othello Reis, já mencionado anteriormente, com dois trabalhos referentes ao tema e ao debate da presença da Álgebra na escola elementar.

Francisco Cabrita, engenheiro, foi nomeado, no final do século XIX (TELEGRAMMAS..., 1897, p. 1), diretor da instrução pública no Rio de Janeiro, permanecendo na função até 1909 (TELEGRAMMAS..., 1909, p. 3). Cabrita foi professor da Escola Polytechnica, diretor e professor de geometria na escola normal, no Rio de Janeiro, bem como diretor do Gymnasio Nacional (O CONSELHO..., 1896, p. 1; DIRECTORIA..., 1915, p. 5; TELEGRAMMAS..., 1903, p. 1). O professor veio a falecer em 1923. Já Henrique Souza Jardim também se formou na escola normal, atuou como professor e diretor da escola normal (NO DIA..., 1908, p. 1; CURSO..., 1911, p. 3), bem como foi banca de concursos vinculados à educação (O CONCURSO..., 1916, p. 3), além de ter atuado como diretor escolar (DIRECTORIA..., 1911, p. 7). A professora normalista (PELAS..., 1914, p. 6) Iracema Torrents Pereira também atuou como diretora (PELO..., 1930, p. 7). Por fim, Othello de Souza Reis foi estudante do Gymnasio Nacional (EXTERNATO..., 1905, p. 2) e depois professor e vice-diretor do Colégio Pedro II (GAZETAS..., 1922, p. 1; COLLEGIO..., 1930, p. 421)), além de professor da escola normal (ESCOLA..., 1925, p. 413). Othello Reis também foi autor de livros didáticos como “Algebra - primeiros passos”.

Nas publicações, foram observados alguns temas principais que são possíveis de destacar: os posicionamentos a respeito de uma Álgebra na instrução elementar e evidências da circulação a favor deste movimento; os conteúdos e abordagem desta Álgebra; a necessidade e sua utilização em relação ao ensino de Aritmética. A seguir são melhores apresentadas estas discussões, considerando o que os autores trazem em seus artigos.

\section{Os posicionamentos a respeito de uma Álgebra na instrução elementar e evidências da circulação a favor deste movimento}

Othello Reis começa seu trabalho (REIS, 1917) dizendo que, em uma conversa com a presença de Afranio Peixoto, havia destacado a grande vantagem na introdução de saberes algébricos na escola primária, principalmente em classes complementares. 
Contudo, o autor ainda indica que tal posição foi recebida com “objecções e protesto" por outras pessoas presentes, mesmo que a proposta não tivesse como objetivo trazer a Álgebra para o ensino primário. Reis (1917, p. 268) evidencia ainda que esse movimento "Não se trata de introduzir o ensino da algebra na escola primaria, destacando assim que a Álgebra para o ensino elementar seria uma Álgebra própria para este grau de ensino, e continua dizendo que "o discipulo percebesse a grande vantagem do ensino algebrico, não haveria as antipathias injustificaveis que ora se notam" (REIS, 1917, p. 269).

O autor segue dizendo que encontra na obra de John Walsh pensamento semelhante ao seu, e aproveita para trazer diversos exemplos em seu texto. Em seu livro, Walsh (1911) apresenta um apêndice intitulado "Equational Arithmetic", em que o autor (WALSH, 1911, p. 349 - 350) aponta o crescente interesse na introdução de uma Álgebra nos últimos anos do curso de aritmética. Nesse sentido, segundo afirma o Reis,

Desde que alumnos e professores pratiquem assiduamente nos problemas correntes de arithmetica, não tardarão a se convencer das vantagens que offerece a solução dos mesmos por este processo. Não se arrecearão mais do nome de algebra, a cuja lembrança tremem... com alguma razão, e não comprehenderão mais, como eu não entendo, porque havemos de quebrar a cabeça a encadeiar raciocínios obsoletos, subtis e complicados, quando é mais intelligente e mais expedito pôr o problema em equação e resolver esta. (REIS, 1917, p. 270)

Cabrita também retoma o movimento de "introducção de equações no curso de Arithmetica" (1917b, p. 360), mencionando Walsh e seu livro. O autor (CABRITA, 1917b) aponta que tal discussão já é antiga, trazendo, para além de Walsh, a contribuição de alguns autores franceses para o tema, como Bourlet e Leyssenne, entre outros. Os autores franceses indicam existir receios e oposições em relação à Álgebra uma vez que esta é vista como complexa. Isso seria contraditório, uma vez que a Aritmética, por vezes, utiliza de raciocínios mais abstratos e difíceis, que em muitos casos são inadmissíveis na prática devido à sua complexidade. Assim, a oposição quanto ao uso da Álgebra não se sustentaria, principalmente quando "a applicação da Algebra sustaria immediatamente toda a difficuldade" (LEYSSENNE, 1901, p. 507, apud CABRITA, 1917b, p. 360). Desse modo, o autor também destaca que a sua proposição não é inédita, uma vez que o movimento já vem ocorrendo pelo mundo. 
Em um segundo trabalho, Reis (1918a, 1918b) busca abordar o tema apresentado pela Comissão dos Quinze - grupo estadunidense que foi estabelecido para estudar e propor mudanças e reestruturações para o ensino elementar do país. Uma das conclusões da comissão, e tema do artigo de Reis, foi de se constituir um ensino de Álgebra nos dois últimos anos do ensino elementar (RODRIGUÊS; COSTA, 2019). Reis (1918a) busca, então, abordar uma Álgebra que seria apropriada para este ensino, bem como sua utilização e a motivação de tais saberes neste nível de ensino e ainda aponta que diversos autores abonam suas palavras, entre eles Francisco Cabrita, os franceses Bourlet e Leyssenne, e os estadunidenses Walsh e Wentworth. Assim, o autor indica não ter dúvida de que se deveria e poderia “[...] introduzir na escola primaria o estudo rudimentaríssimo da algebra, sufficiente para a solução de certos problemas" (REIS, 1918a, p. 12).

Pereira (1918a, 1918b) ainda contribui com o tema ao discutir as diversas capacidades a se desenvolver nos estudantes, indicando que a Álgebra, “em seu papel elementar de fornecedora de instrumentos simplificadores do calculo, será um dos esteios a que devemos apoias nossa Arithmetica Primaria” (PEREIRA, 1928a, p. 220). Segundo a autora, é possível observar o avanço de uma matéria sobre a outra, como no caso da fórmula de juros que, mesmo sendo da Álgebra, encontra-se no ensino de Aritmética.

De modo geral, é possível observar que no período das publicações ainda havia grande receio quanto à constituição de uma Álgebra para o ensino elementar brasileiro. Contudo, alguns autores buscam sustentar este movimento com base em perspectivas internacionais, em que tais ideias já estavam sendo discutidas. Ainda foi possível constatar que, na busca por superar os receios quanto a esse ensino, a Álgebra proposta deveria ser concebida para o ensino elementar, e não apenas a tomada da Álgebra do ensino secundário. 


\section{Os conteúdos e abordagem desta Álgebra}

Reis (1917) aponta que a introdução a equações do primeiro grau na resolução de problemas da escola elementar traria vantagens. Tal pensamento seria validado por Walsh (1911), uma vez que este último destaca a crescente perspectiva do ensino de equações nos últimos anos do curso de aritmética. Segundo Walsh (1911), este ensino não deveria ser iniciado por definições, mesmo de incógnitas, mas com a resolução de questões como " $2+$ ? = 4 " ou " $5 \times ?=30$ ".

No que se refere aos saberes algébricos, conforme Reis (1917), o estudante poderia escrever $12 x$ da mesma maneira que escreve " 12 penas" ou " 12 objetos". Deste modo o autor indica como se somariam termos desse tipo, indicando que se houvesse $12 x$ e $7 x$ (como 12 penas e 7 penas), o estudante indicaria quantos objetos $x$ existem, realizando a soma $12 x+7 x=19 x$. "Insista-se bem que a é um objecto, b é outro, $\mathrm{m}$ um terceiro. Por ahi é que começa a confusão do espirito no aprendizado da algebra" (REIS, 1917, p. 269). Segundo o autor, é a partir dessa relação da incógnita com o objeto real que o estudante compreenderia as operações algébricas.

Com a proposição de um ensino gradual, após a resolução de equações como $x+3=7$ e $3 x=6$ por meio da tentativa e erro, ou pelo raciocínio "um número que somado a 3 resulta em 7" ou "um número que multiplicado por 3 tem resultado 6", o autor indica que "basta ensinar que, para transpôr, isto é, para passar o 7 para o segundo membro, é sufficiente apagal-o no primeiro, e escrevel-o no segundo com signal trocado" (REIS, 1917, p. 269). Após o ensino de equações o professor deveria, segundo o autor (REIS, 1917), ensinar "summariamente o modo pelo qual se procede com systemas de 2 equações a 2 incognitas" (p. 269), pode-se fazer o uso do método de substituição para a resolução. Por fim, o professor deveria trabalhar com os estudantes "pôr o problema em equação", o que os auxiliaria a lidar com equações. O autor ainda ressalta, em outro trabalho, que "não devamos chegar logo ás equações do $2^{\circ}$ gráo, mas as do $1^{\circ}$ podem ser, sem difficuldade" (REIS, 1918a, p. 12).

Em um segundo trabalho, Reis (1918a) destaca que seria necessário fazer o estudante compreender o que é uma equação. Para isso, o professor traz a ideia da balança, que os estudantes saberiam para que serve e como operá-la. 
Supponhamos collocados na concha da esquerda 3 daquelles objectos a que chamámos $x$. Há, pois, no prato, 3x. O peso desses tres objectos é, ainda imaginado, 200 grammas. Se collocarmos na concha do lado direito pesos equivalentes a 200 grammas, o travessão da balança ficará em equilibrio, e esse equilibrio será representado pela expressão $3 x=200$. Podemos agora dizer ao alumno, sem definição formal, que esta expressão de equilibrio é uma equação, que a parte á esquerda é o primeiro membro, e a da direita o segundo. (REIS, 1918a, p. 14)

Para o autor, se fosse colocado/retirado um peso de $50 \mathrm{~g}$ de um lado da balança, o equilíbrio se perderia. Para se corrigir o desequilíbrio o estudante compreenderia ser necessário colocar/retirar um peso de $50 \mathrm{~g}$ no outro lado da balança, obtendo-se novamente o equilíbrio, representado pela equação $3 x \pm 50=200 \pm 50$.

Em sua conferência, Reis (1918b) ainda apresenta equações com duas incógnitas. Segundo ele, seriam necessárias duas equações para resolver o que ele define como “systema”. Para a resolução não deveriam ser utilizados diversos métodos, apenas um, o da "eliminação de uma das incognitas pela reducção ao mesmo coefficiente" (REIS, 1918b, p. 42). Para isso, o professor faria uso novamente do princípio de equilíbrio da balança, subtraindo os lados equivalentes (membro a membro) de uma equação na outra. Figura também, na fala de Reis (1918b), a presença do ensino de números negativos, nesse ensino de Álgebra voltado aos últimos anos da instrução elementar, sendo destacada a necessidade da abordagem destes em relação aos números distribuídos em uma linha ou do termômetro.

Ahi tendes, Snrs. Professores, o sufficiente para a resolução de quase todos os problemas difficeis, ou cuja solução é penosa de explicar em palavras. Não hesito em crêr que achaes, assim, perfeitamente simplificada a tarefa do ensino preliminar, ou introductorio, desta sciencia, tão injustamente tida por difficil. (REIS, 1918b, p. 43)

Já Cabrita inicia o artigo apresentando um programa que "julgava ser suficiente para um curso de algebra na referida escola [normal]" (CABRITA, 1917a, p. 299, grifo dos autores). Segundo o autor, sua indicação para o curso de Álgebra foi:

$1^{\circ}$ Anno: - Estudo de uma série bem graduada de problemas, por meio da linguagem algébrica, que conduzem á noção de equação (do $1^{\circ}$ grau a uma só incógnita) e ás transformações necessárias á essa resolução. 
Resolução prévia de algum desses problemas pelo simples raciocínio e só com os recursos da Arithmetica, para mostrar a utilidade da linguagem algébrica e como esta facilita a resolução dos problemas, orientando muitas vezes a marcha do raciocínio e encaminhando o processo arithmetico de resolução.

$2^{\circ}$ Anno: - Continuação do estudo da série de problemas iniciado no $1^{\circ}$ anno e extensão do methodo algébrico aos problemas a mais de uma incógnita, que conduz á noção de systema de equações e aos methodos de eliminação por adicção ou subtracção, por substituição e por comparação, com a resolução prévia de alguns desses problemas por simples raciocínio. (CABRITA, 1917a, p. 299)

A Álgebra do programa de Cabrita aparenta refletir o posicionamento de Walsh, uma vez que sugere ao futuro professor o aprendizado de conteúdos voltados à resolução de equações e sistemas lineares, o que faria com que o professor possuísse conhecimento mais aprofundado do que Walsh propõe aos estudantes.

Quanto aos conteúdos da Álgebra no ensino elementar, Cabrita (1917b) apresenta ao fim de seu artigo que a Álgebra "que se pretende inculcar ao professor primario", apoiada também em autores franceses, tem como objetivo o estudo elementar de equações, de forma que estes saberes servissem de subsídio para o ensino de Aritmética. Aqui, novamente, os saberes de um ensino de Álgebra podem ser percebidos sob a perspectiva de ferramentas para a Aritmética.

Alguns anos depois, ao discutir a educação brasileira, Cabrita (1921) apresenta a criação de diversas cadeiras, inclusive uma de Álgebra no ensino secundário em 1809, bem como sobre o "methodo do ensino mutuo". Discussões mais aprofundadas acerca do ensino de Álgebra, como as que se busca nesta pesquisa, que não são feitas. Contudo, é possível observar que o documento a que Cabrita se refere (BRASIL, 1809) estabelece a cadeira de "Arithmetica, Algebra e Geometria", em que os conteúdos de "resolução das equações algebricas do $I^{\circ}$ e e $2^{\circ}$ gráo" se fariam presentes. Merece destaque que, 100 anos depois, a proposta de Cabrita (1917a) para o ensino normal traz uma Álgebra sem as equações do $2^{\circ}$ grau.

Sob a perspectiva de Pereira (1928a, p. 221), o ensino de Aritmética deveria “assegurar, tanto quanto possivel, o caminho á resolução de quaesquer questões de sua alçada, independentemente de normas preestabelecidas". Assim, deveria se buscar por métodos gerais para resolver problemas ou, como indica a autora, metodizar o raciocínio 
do estudante. Dessa forma, sem que o professor resolva o problema, ele daria os esclarecimentos, não comprometendo a tarefa que deveria ser executada pelo estudante.

Na segunda parte do seu artigo, Pereira (1928b) apresenta diversos problemas que podem ser abordados a partir de temas ou imagens, sendo que suas soluções poderiam ser abordadas como "solução geral” e, em seguida, "solução numérica".

III) Uma caixinha de lapis de côr contém tantos lapis. Quantos lapis haverá em tantas caixas?

Solução geral: Total de lapis $=n .^{\circ}$ de lapis que há em uma caixinha $\mathrm{X} n .^{\circ}$ de caixinhas.

(forneçam-se os dados numericos: meia dezena de caixas, contendo, cada uma, a metade de meia duzia de lapis).

Solução numerica: Total de lapis: 5 X $3=15$. (PEREIRA, 1928b, p. 249)

De acordo com a autora, a introdução da incógnita em problemas desse tipo seria oportuna, como, por exemplo, $4+x=10$ ou $2 x=16$. Pereira (1928b, p. 249) aponta que essas equações "serão o inicio da Algebra na escola primaria, estudo que será feito gradativamente, como já nos mostrou o illustre professor Dr. Othello Reis". Outra proposta apresentada no artigo é o uso de problemas envolvendo regra de três, apresentando também um processo generalizado e aplicando valores ao problema.

Assim, é possível observar, segundo os posicionamentos encontrados, que a Álgebra do ensino elementar estaria limitada ao ensino de equações, aparentemente até as do primeiro grau, apenas, sistemas lineares e números negativos. Também são destacados o uso da balança e da relação da incógnita com objetos como elementos facilitadores do ensino desses novos saberes na instrução elementar. Além disso, esse ensino de Álgebra estaria intimamente relacionado com o ensino de Aritmética e a resolução de problemas. 


\section{A necessidade e utilização desta Álgebra em relação ao ensino de Aritmética}

Reis (1917) reforça a perspectiva de que o estudo de equações estaria atrelado a problemas, sem indicar se estes seriam de Aritmética, somente deixando esta relação explícita em seu segundo artigo (REIS, 1918a, 1918b). O autor ainda destaca, em relação a este ensino de Álgebra, que a resolução de problemas por equação também permitiria ao estudante perceber a importância destes estudos no ensino elementar. Nesse sentido, Cabrita (1917b) reforça esta perspectiva ao apresentar ao leitor que o ensino de Álgebra não deveria ser temido, uma vez que uma de suas finalidades é de facilitar a resolução de diversos problemas em Aritmética e, deste modo, a própria aprendizagem do estudante.

Os "certos problemas" - termo utilizado por Reis (1918a) para se referir a problemas complexos de Aritmética -, seriam problemas em que a resolução exige um raciocínio extenso e cansativo. $\mathrm{O}$ autor segue dizendo que mesmo descrever o raciocínio para a resolução do problema pode ser complexo e que exemplos poderiam ser colhidos em cadernos escolares, como:

Um negociante comprou um rebanho de carneiros a tres preços diversos. Pagou 1/3 do rebanho á razão de 21 francos a cabeça; $2 / 5$ á razão de 19 francos e o resto á razão de 15 francos. Revendeu todo o rebanho por 1.674 francos, ganhando $1 / 5$ do preço de compra. De quantos carneiros se compunha o rebanho? (REIS, 1918b, p. 41)

De acordo com Reis, é complexa a resolução de tal problema apenas fazendo uso de saberes aritméticos, mas que o processo seria mais fácil desde que se fizesse uso de saberes algébricos e do emprego da equação.

Na primeira parte do seu artigo, Jardim (1918a, p. 219) se propõe a "estudar a resolução de problemas na classe média e complementar", e para isso indica que não há regras para a resolução de problemas da Aritmética, mas que princípios gerais podem ser tomados, indicando, por exemplo, que na Álgebra tem-se "representar as incognitas por letras e depois, suppondo o problema resolvido, procurar verifical-o" (JARDIM, 1918a, p. 219). Na segunda parte do artigo o autor começa recapitulando alguns problemas do ensino nas aulas de Aritmética, de modo que critica o uso da sequência "passar 
problemas para casa", "não corrigir os problemas na presença dos estudantes" e "distribuir notas geralmente baixas".

Segundo Jardim (1918b, p. 250), ao fazer isso o professor não só exigiria do aluno algo que não lhe ensinou - a resolver os problemas -, mas também "para inimizar com a arithmetica alumnos de incontestavel merito e que poderiam fazer excellente figura nesta matéria." O autor também busca discutir a importância da resolução de exercícios em sala de aula, junto com os estudantes, e de que os mesmos sejam análogos em relação aos tipos já conhecidos, não necessariamente ao tema. Todavia o autor não explicita se em algum momento o uso da Álgebra seria sugerida ou se poderia surgir nas resoluções dos problemas, mesmo no ensino complementar.

Na formação de professores, Cabrita (1917a, p. 299) apresenta, com o programa pensado para os normalistas, que a Álgebra possibilitaria "preparo necessario e sufficiente para pôr em prática, [...] o que pensa John Walsh sobre a resolução de problemas na escola primária [...]." O pensamento de Walsh, ao qual Cabrita se refere, diz respeito à resolução algébrica de problemas que seriam comumente resolvidos aritmeticamente e, portanto, a Álgebra do ensino normal prepararia o normalista para utilizar estes saberes como ferramenta para no ensino elementar.

Em um outro artigo (CABRITA, 1922), o autor propõe um processo para determinar as soluções inteiras e positivas de uma equação do primeiro grau com duas incógnitas. Uma nota de redação da revista é apresentada logo ao início, apontando Cabrita "como um dos mais altos e significativos expoentes do magistério brasileiro" e justificando a presença do artigo na revista, ao ressaltar que o periódico é voltado aos professores da escola primária, incluindo o debate na área de formação de professores (CABRITA, 1922, p. 99).

A revista indica que o processo abordado por Cabrita (1922, p. 99) seria inédito, uma vez que a nota termina indicando que "Não conhecemos processo algum que com elle possa, legitimamente, ser confundido, é cuidadosa pesquiza, [...], confirmou a apreciação, que imediatamente haviamos feito, considerando-o original." Desse modo, a discussão apresentada demonstra pertencer a um nível muito superior ao do ensino elementar, mas ainda fazendo parte da formação do professorado. Isso realça uma perspectiva de que o professor devesse deter conhecimentos que vão além dos 
lecionados em sala de aula e que a Álgebra de sua formação se constituiria como uma ferramenta para sua atuação no ensino elementar.

Assim, como se percebe neste tema e no anterior, a Álgebra proposta para o ensino elementar deveria possuir grande relação ao ensino de Aritmética e a facilitação no processo de resolução de problemas desta última. Os problemas complexos de Aritmética, com resoluções exaustivas e desnecessárias, são também um dos suportes para o movimento a favor da constituição de uma Álgebra para o ensino elementar. Essa perspectiva também pode ser observada no final do século XIX com os estudos desenvolvidos pelas comissões estadunidenses (RODRIGUÊS; COSTA, 2019). Por fim, a Álgebra do ensino elementar e a Álgebra da formação do professor assumiriam assim, por vezes, a perspectiva de uma ferramenta para o ensino de Aritmética.

\section{Até onde a pesquisa nos permite enxergar}

A partir da leitura atenta dos artigos, foi possível observar que, em pouco mais de dez anos, algumas das publicações na revista "A Escola Primaria" fizeram circular no Brasil temas acerca da Álgebra. Em pouco mais da metade dos trabalhos é observada também a discussão sobre o ensino de Álgebra na escola elementar, também denominada de "escola primaria", ou da utilização e ensino de saberes algébricos para o ensino de Aritmética. As publicações destacam ainda a recorrente afirmação do uso da álgebra para a resolução de problemas aritméticos, ao ensino da generalização e o abandono de raciocínios longos e obsoletos na resolução de problemas da Aritmética.

Quanto a uma possível abordagem de saberes algébricos no ensino elementar, fazse presente a ideia de incógnita e as operações algébricas, bem como a ideia de operar algebricamente, a partir de uma relação com objetos reais, quando se entende $5 x \operatorname{como} 5$ penas, por exemplo. Do mesmo modo, as equações do primeiro grau são conteúdos que recebem grande enfoque nos artigos que realmente se debruçam sobre a Álgebra, do mesmo modo que os sistemas lineares. Além disso, pode-se perceber a discussão a respeito de uma formação de professores que detivesse conhecimento superior ao que é lecionado em sala de aula, mas em um programa que fosse ao encontro do que era apontado para os saberes algébricos no ensino elementar. 
É igualmente relevante destacar a busca, em alguns trabalhos, por fazer circular no país os autores e posicionamentos estrangeiros, como a Comissão dos Quinze e John Walsh dos Estados Unidos e Garnier e Leyssenne da França, de modo a fortalecer o debate da Álgebra no Brasil. Ademais, com as apropriações dos referenciais estrangeiros, os autores da revista "A Escola Primaria" também permitiram que circulasse $\mathrm{O}$ movimento para a institucionalização de um ensino de Álgebra para o ensino elementar, distinta da presente no ensino secundário, tendo como conteúdos os princípios algébricos, equações e sistemas, bem como o foco na simplificação da resolução de problemas complexos da Aritmética.

\section{Referências}

BRASIL. Indice das decisões de 1809: N. 29.- Brazil.- resolução de consulta da mesa do desembargo do paço de 14 de julho de 1809. p. 28-30. [Brasília]: Câmara Legislativa, 1809. Disponível em:

https://bd.camara.leg.br/bd/bitstream/handle/bdcamara/18321/colleccao_leis_1809_parte2 .pdf. Acesso em: 20 dez. 2020.

BURKE, Peter. O que é história do conhecimento? 1. ed. São Paulo: Ed. Unesp, 2016.

CABRITA, Francisco. A algebra do normalista. A Escola Primária, Rio de Janeiro, ano 1, n. 10, p. 299-300, 1917a.

CABRITA, Francisco. A algebra no ensino primario. A Escola Primária, Rio de Janeiro, ano 1, n. 12, p. 360-361, 1917b.

CABRITA, Francisco. Escola normal. A Escola Primária, Rio de Janeiro, ano 2, n. 3, p. 66-67, 1917C.

CABRITA, Francisco. Memoravel periodo historico da Instrucção Nacional. A Escola Primária, Rio de Janeiro, ano 5, n. 2, p. 35-36, 1921.

CABRITA, Francisco. Analyse indeterminada. A Escola Primária, Rio de Janeiro, ano 6, n. 4, p. 99-101, 1922. 
CATANI, Denice Barbara. A imprensa periódica educacional: as revistas de ensino e o estudo do campo educacional. Educação e Filosofia, Uberlândia, v. 10, n. 20, p. 115-130, 1996. Disponível em:

http://www.seer.ufu.br/index.php/EducacaoFilosofia/article/view/928/842. Acesso em: 20 abr. 2020.

CERTEAU, Michel de. A escrita da história. Rio de Janeiro: Forense Universitária, 2010. 345 p.

CHARTIER, Roger. A história cultural entre práticas e representações. Rio de Janeiro: Berthand do Brasil, 1990.

COLLEGIO Pedro II. Almanak Laemmert : Administrativo, Mercantil e Industrial, Rio de Janeiro, ano 86, p. 421, 1930. Disponível em:

http://memoria.bn.br/DocReader/313394/103914. Acesso em: 9 nov. 2021.

COSTA, David Antonio da. O repositório de conteúdo digital: um exemplo didático a partir dos impressos pedagógicos. In: SEMINÁRIO TEMÁTICO SABERES ELEMENTARES MATEMÁTICOS DO ENSINO PRIMÁRIO (1890-1970), 12., 2015, Curitiba. Anais [...]. Curitiba: PUCPR, 2015. p. 436-444. Tema: o que dizem as revistas pedagógicas? Disponível em: http://www2.td.utfpr.edu.br/seminario_tematico/ANAIS/37_COSTA.pdf. Acesso em: 20 abr. 2020.

CURSO normal. O Paiz, ano XXVIII, n. 9899, p. 3, 13 nov. 1911. Disponível em: http://memoria.bn.br/DocReader/178691_04/9218. Acesso em: 9 nov. 2021.

DIRECTORIA geral de instrucção publica. O Imparcial: Diario Illustrado do Rio de Janeiro, Rio de Janeiro, ano IV, n. 839, p. 5, 20 abr. 1915. Disponível em:

http://memoria.bn.br/docreader/107670_01/10347. Acesso em: 9 nov. 2021.

DIRECTORIA geral de instrucção publica. O Paiz, ano XXVII, n. 9746, p. 7, 13 jun. 1911.

Disponível em: http://memoria.bn.br/DocReader/178691_04/7152. Acesso em: 9 nov. 2021.

ESCOLA Normal. Almanak Laemmert: Administrativo, Mercantil e Industrial, Rio de Janeiro, ano 81, p. 413, 1925. Disponível em:

http://memoria.bn.br/DocReader/313394/88073. Acesso em: 9 nov. 2021.

EXTERNATO do Gymnasio mineiro. Minas Geraes: Orgam Official dos Poderes do Estado, Ouro Preto, ano VIII, n. 197, p. 8, 29 jul. 1899. Disponível em:

http://memoria.bn.br/DocReader/291536/16728. Acesso em: 9 nov. 2021.

EXTERNATO do Gymnasio Nacional. Jornal do Brasil, Rio de Janeiro, ano XV, n. 25, p. 2, 25 jan. 1905. Disponível em: http://memoria.bn.br/DocReader/030015_02/15732. Acesso em: 9 nov. 2021. 
FERREIRA, Norma Sandra de Almeida. As pesquisas denominadas "estado da arte". Educação \& Sociedade, Campinas, ano XXIII, n. 79, p. 257-272, 2002. Disponível em: http://www.scielo.br/pdf/es/v23n79/10857.pdf. Acesso em: 20 abr. 2020.

GAZESTAS e compêndios. Pacotilha, Maranhão, ano XLII, n. 50, p. 1, 2 mar. 1922. Disponível em: http://memoria.bn.br/DocReader/168319_02/15587. Acesso em: 9 nov. 2021.

JARDIM, Henrique Souza. Problemas de arithmetica na escola primaria: como ensinar a resolvel-os. A Escola Primária, Rio de Janeiro, ano 2, n. 9, p. 218-219, 1918 a.

JARDIM, Henrique Souza. Problemas de arithmetica na escola primaria: como ensinar a resolvel-os (continuação). A Escola Primária, Rio de Janeiro, ano 2, n. 10, p. 249 - 252, 1918b.

NO DIA 22 de Outubro próximo... O Fluminense, Niterói, ano 31, n. 7136, p. 1, 27 set. 1908. Disponível em: http://memoria.bn.br/DocReader/100439_04/11387. Acesso em: 9 nov. 2021.

NOTICIARIO. Minas Geraes : Orgam Official dos Poderes do Estado, Ouro Preto, ano I, n. 226, p. 3, . Disponível em: http://memoria.bn.br/DocReader/291536/1305. Acesso em: 9 nov. 2021.

O CONCURSO de auxiliares de ensino. A Noite, Rio de Janeiro, ano VI, n. 1484, p. 3, 7 fev. 1916. Disponível em: http://memoria.bn.br/DocReader/348970_01/7997. Acesso em: 9 nov. 2021.

O CONSELHO de instrucção publica... Gazeta da Tarde, Rio de Janeiro, ano XVII, n. 308, p. 1, 6 nov. 1896. Disponível em: http://memoria.bn.br/docreader/226688/15993. Acesso em: 9 nov. 2021.

OLIVEIRA, Mariza da Gama Leite de. Debates e embates na instrução pública primária e seus efeitos nas práticas do Instituto Ferreira Vianna (Rio de Janeiro, 1929 - 1940). 2015. 378f. Tese (Doutorado em Educação) - Universidade Federal do Rio de Janeiro, Programa de Pós-Graduação em Educação, Rio de Janeiro, 2015.

OLIVEIRA FILHO, Francisco. As revistas pedagógicas e o ensino de frações: um artigo de Benedicto Galvão. In: SEMINÁRIO TEMÁTICO SABERES ELEMENTARES MATEMÁTICOS DO ENSINO PRIMÁRIO (1890-1970), 12., 2015, Curitiba. Anais [...]. Curitiba: PUCPR, 2015. p. 157167. Tema: o que dizem as revistas pedagógicas? Disponível em: http://www2.td.utfpr.edu.br/seminario_tematico/ANAIS/12_OLIVEIRA_FILHO.pdf. Acesso em: 20 abr. 2020.

PELAS escolas. O Paiz, Rio de Janeiro, ano XXIX, n. 10.714, p. 6, 6 fev. 1914. Disponível em: http://memoria.bn.br/DocReader/178691_04/21468. Acesso em: 9 nov. 2021.

PELO Brasil unido e forte. Diario de Noticias, ano I, n. 186, p. 7, 12 dez. 1930. Disponível em: http://memoria.bn.br/DocReader/093718_01/2887. Acesso em: 9 nov. 2021. 
PEREIRA, Iracema Torrents. Do ensino de mathematica na escola primaria. A Escola Primária, Rio de Janeiro, ano 7, n. 7, p. 220-224, 1928 a.

PEREIRA, Iracema Torrents. A mathematica na escola primaria (continuação). A Escola Primária, Rio de Janeiro, ano 7, n. 8, p. 248-256, 1928 b.

REIS, Othello de Souza. Os problemas resolvidos por equações. A Escola Primaria, Rio de Janeiro, ano 1, n. 9, p. 268-271, 1917.

REIS, Othello de Souza. Os dois ultimos annos de arithmetica, na escola primaria, segundo a Comissão dos quinze. A Escola Primaria, Rio de Janeiro, ano 3, n. 1, p. 11-15, 1918 a.

REIS, Othello de Souza. Os dois ultimos annos de arithmetica, na escola primaria, segundo a Comissão dos quinze (continuação). A Escola Primaria, Rio de Janeiro, ano 3, n. 2-3, p. $41-43,1918 b$.

RODRIGUÊS, Jeremias Stein; COSTA, David Antonio da. A Comissão dos Quinze e os Primeiros Movimentos acerca do ensino da álgebra na escola primária brasileira. Acta Scientiae, Canoas, v. 21, n. 6, p. 150-172, 2019. Disponível em: http://www.periodicos.ulbra.br/index.php/acta/article/viewFile/5450/pdf_1. Acesso em: 20 abr. 2020.

ROMANOWSKI, Joana Paulin; ENS, Romilda Teodora. As pesquisas denominadas do tipo "estado da arte" em educação. Diálogo Educacional, Curitiba, v. 6, n. 19, p. 37-50, set./dez. 2006. Disponível em: https://www.redalyc.org/pdf/1891/189116275004.pdf. Acesso em: 20 abr. 2020.

TELEGRAMMAS do interior. Correio Paulistano, São Paulo, ano 28, p. 1, 16 jan. 1903. Disponível em: http://memoria.bn.br/docreader/090972_06/2315. Acesso em: 9 nov. 2021.

TELEGRAMMAS serviço especial do ‘Commercio de Joinville’. Commercio de Joinville, Joinville, ano V, n. 220, p. 3, 24 jul. 1909. Disponível em:

http://memoria.bn.br/docreader/886173/691. Acesso em: 9 nov. 2021.

TELEGRAMMAS serviço particular do diário. Diario de Pernambuco, Pernambuco, ano LXXIII, n. 275, p. 1, 8 dez. 1897. Disponível em:

http://memoria.bn.br/DocReader/029033_07/17663. Acesso em: 9 nov. 2021.

VALENTE, Wagner Rodrigues. Oito temas sobre historia da educação matemática.

REMATEC, Natal, Ano 8, n. 12, p. 22-50, 2013. Disponível em:

https://core.ac.uk/download/pdf/38424062.pdf. Acesso em: 20 abr. 2020.

VALENTE, Wagner Rodrigues. História da educação matemática: considerações sobre suas potencialidades na formação do professor de matemática. Boletim de Educação Matemática, Rio Claro, v. 23, n. 35, p. 123-136, 2010. Disponível em: https://repositorio.ufsc.br/bitstream/handle/123456789/160381/3735-18103-1-PB1.pdf. Acesso em: 20 abr. 2020. 
VALENTE, Wagner Rodrigues. História da Educação Matemática: interrogações metodológicas. REVEMAT, Florianópolis, v. 2, n. 2, p. 28-49, 2007. Disponível em: https://periodicos.ufsc.br/index.php/revemat/article/view/12990. Acesso em: 20 abr. 2020.

VALENTE, Wagner Rodrigues. A matemática escolar: perspectivas históricas. In: CONGRESSO LUSO-BRASILEIRO DE HISTÓRIA DA CIÊNCIA E DA TECNOLOGIA, 2., 2003, Rio de Janeiro. Anais [...]. Rio de Janeiro: Sociedade Brasileira de História da Ciência, 2003. Disponível em:

http://www.sbhe.org.br/novo/congressos/cbhe3/Documentos/Individ/Eix01/030.pdf.

Acesso em: 20 abr. 2020.

VEYNE, Paul Marie. Como se escreve a história. Brasília: Editora Universidade de Brasília, 1995.

VOSGERAU, Dilmeire Sant'Anna Ramos; ROMANOWSKI, Joana Paulin. Estudos de revisão: implicações conceituais e metodológicas. Diálogo Educacional, Curitiba, v. 14, n. 41, p. 165189, jan./abr., 2014. Disponível em:

https://periodicos.pucpr.br/index.php/dialogoeducacional/article/view/2317/2233. Acesso em: 20 abr. 2020.

WALSH, John Henry. Practical methods in arithmetic. Nova York: D. C. HEATH \& CO, 1911. 